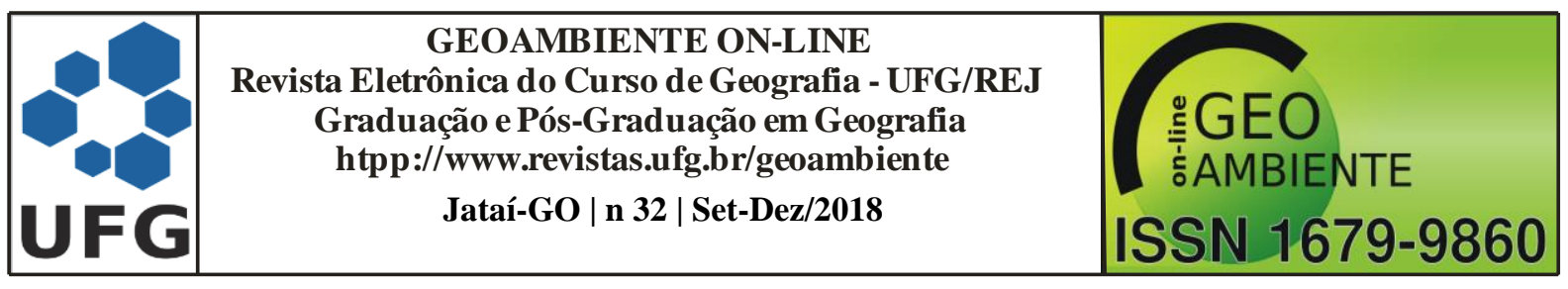

\title{
ENQUADRAMENTO DE CORPOS DE ÁGUA: UM INSTRUMENTO DA POLÍTICA NACIONAL DE RECURSOS HÍDRICOS
}

\author{
Neilson Rocha da Silva, Thiago de Noroes Albuquerque \\ (Instituto Federal de Educação Ciência e Tecnologia do Ceara - IFCE, Mestre em Tecnologia \\ e Gestão Ambiental, neilsonrocha@outlook.com.br, thiago.noroes12@ hotmail.com)
}

Resumo: O enquadramento dos corpos de água é um instrumento previsto nas Políticas de Recursos Hídricos em âmbito Nacional e Estadual, outros instrumentos normativos internacionais abordam esse tema regulamentando em situações especificas a qualidade de água desejada para as diferentes atividades que se procuram atender. No Brasil, os instrumentos previstos na Lei nº 9.433 de 1997 Política Nacional dos Recursos Hídricos quando aplicados de maneira conjunta asseguram a manutenção e melhoria da qualidade das águas utilizadas pelas populações, permitindo assim, a sua utilização para diferentes atividades, fundamento esse que se encontra expresso no seu artigo $1^{\circ}$ assegurando os usos múltiplos dos recursos hídricos. Os Estados regulamentam normativas especificas embasada na legislação Federal, acrescido das peculiaridades existentes em cada Estado, permitindo uma maior eficiência na aplicação dos Instrumentos. O Instrumento de enquadramento dos recursos hídricos é necessário a manutenção da qualidade das águas, encontra-se ativamente implantado e difundido no país e permite através de sua implantação a busca por uma melhor qualidade das águas utilizadas nas bacias hidrográficas.

Palavras-chave: Legislação, Enquadramento, Recursos Hídricos.

\section{WATER BODY CLASSIFICATION: AN INSTRUMENT OF THE NATIONAL POLICY OF WATER RESOURCES.}

Abstract: The Water Classification is an instrument that belongs to the Water Resources Policies at the national level and statewide, other international normative instruments addressed this subject regulating in specific situations the quality of water desired to serve different activities. In Brazil, the instruments provided by law 9.433 of 1997 Nacional Politics about Water Resources, when they are applied in an integrated way, ensure the permanence and

Artigo recebido para publicação em 28 de Agosto de 2018

Artigo aprovado para publicação em 30 de Novembro de 2018 


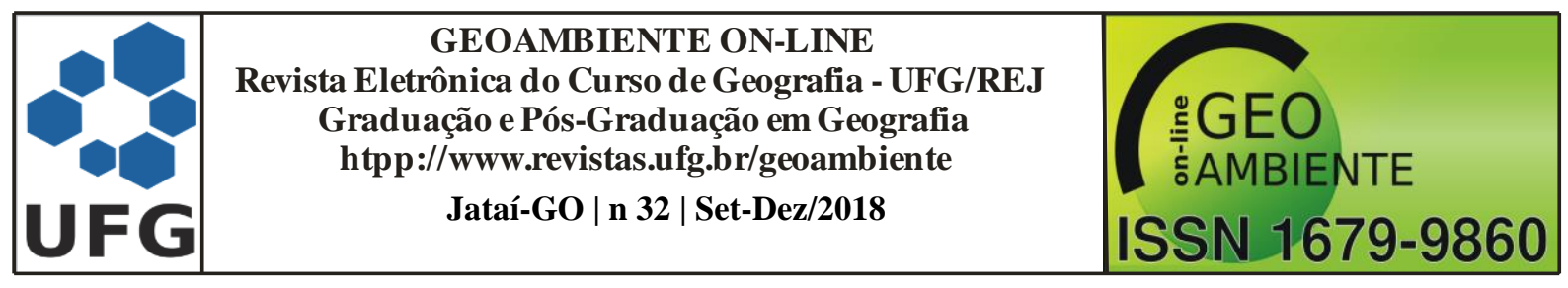

improvement of the quality of water used by populations, thus allowing its use for different activities, which is expressed in the article $1^{\circ}$ of this law, ensuring the multiple uses of water resources. The States regulate specific guidelines based on Federal legislation, adding the peculiarities existing in each State, what allowing greater efficiency in the application of the Instruments. The instrument of water resources classification scheme is necessary to maintain the quality of water, it's actively deployed and diffused in the country and allows through its implementation the search for a better quality of the waters used in the watershed.

Keywords: Legislation, Water classification, Water resources.

\section{ENCUADRAMIENTO DE CUERPOS DE AGUA: UN INSTRUMENTO DE LA POLÍTICA NACIONAL DE RECURSOS HÍDRICOS.}

Resumen: El encuadramiento de los cuerpos de agua es un instrumento previsto en las Políticas de Recursos Hídricos en ámbito Nacional y Estadual, otros instrumentos normativos internacionales abordan ese tema regulando en situaciones específicas la calidad de agua deseada para las diferentes actividades que se buscan atender. En Brasil, los instrumentos previstos en la Ley nº 9.433 de 1997 - Política Nacional de los Recursos Hídricos cuando aplicados de manera conjunta aseguran el mantenimiento y la mejora de la calidad de las aguas utilizadas por las poblaciones, permitiendo así su utilización para diferentes actividades, fundamento este que se encuentra expresado en su artículo 1, garantizando los usos múltiples de los recursos hídricos. Los Estados regulan normativas específicas basadas en la legislación Federal, em adición las peculiaridades existentes en cada Estado, permitiendo una mayor eficiencia en la aplicación de los Instrumentos. El Instrumento de encuadramiento de los recursos hídricos es necesario para el mantenimiento de la calidad de las aguas, se encuentra activamente implantado y difundido en el país y permite a través de su implantación la búsqueda de una mejor calidad de las aguas utilizadas en las cuencas hidrográficas.

Palabras-chave: Legislación, encuadramiento, Recursos Hídricos.

\section{INTRODUÇÃO}

As atividades desenvolvidas pelo homem por muitas vezes têm por objetivo gerar benefícios e desenvolvimento econômico. Buscando-se a continuidade de seu desenvolvimento a sociedade tende a se utilizar de práticas de exploração dos recursos naturais sem a devida proteção ambiental. As práticas de exploração sem os devidos cuidados podem produzir 


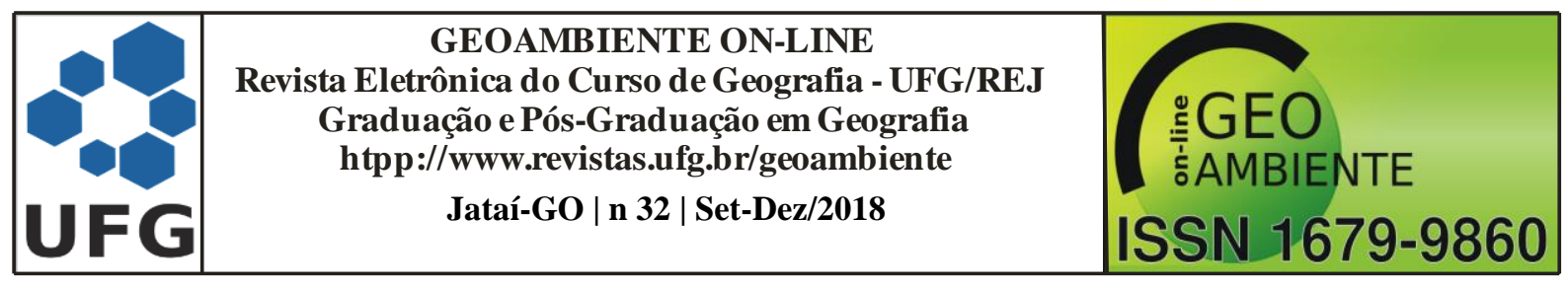

benefícios até um momento ápice, determinado pela capacidade suporte do ambiente, assim, quando ultrapassada, passa a produzir mais malefícios do que vantagens. A continua exploração dos recursos naturais de maneira imprudente impede a manutenção da qualidade ambiental podendo causar sérios danos ao ser humano e ao meio ambiente (BARBOSA, 2008).

Neste sentido, a Declaração da Conferência da ONU no Ambiente Humano de 1972 estabelece em seus princípios que os recursos naturais da terra entre eles a água deve ser preservada em benefício das gerações presentes e futuras, mediante sua cuidadosa planificação ou ordenamento (ESTOCOLMO, 1972). Desta maneira, a partir da Conferência de Estocolmo diversos países passam a reestruturar e/ou formular suas políticas ambientais.

No Brasil foi instituído a Política Nacional de Recursos Hídricos (PNRH) depois de 25 anos da Conferência de Estocolmo, buscando proporcionar uma gestão dos recursos hídricos. Essa política busca assegurar entre outros, os uso múltiplos das águas, permitindo que diferentes práticas sejam executadas em conjunto e assegurando uma qualidade satisfatória de água no exutório da bacia hidrográfica (BRASIL, 1997).

A Política Nacional dos Recursos Hídricos Lei n 9433 de 1997 apresenta dentre os seus fundamentos a necessidade de uma gestão descentralizada, essa gestão assegura a participação da sociedade e dos utilizadores dos recursos hídricos na tomada de decisão e é construída através de uma estrutura denominada Comitê de Bacia Hidrográfica, sendo um dos mecanismos utilizados pela sociedade para promover debates sobre questões que direta e indireta afetam os recursos hídricos como o estabelecimento de mecanismos de cobrança pelo uso da água e a manutenção dos usos múltiplo do recurso hídrico, permitindo assim o desenvolvimento de diferentes práticas, mas assegurando a sua utilização de forma sustentável (BRASIL, 1997).

A política também apresenta o recurso hídrico com um bem natural dotado de valor econômico em que através de sua utilização e beneficiamento ocorre a possibilidade de gerar receita, através da qual se torna possível a implementação e o custei das práticas de gestão ambiental implantadas na bacia hidrográfica o qual o recurso hídrico está inserido (BRASIL, 1997).

Nesse contexto, cria-se o enquadramento de corpos de água que é um dos instrumentos previstos na PNRH, esse instrumento consiste na previsão em classes, segundo os usos preponderantes da água. No art. $9^{\circ}$ diz que o enquadramento dos corpos de água, visa assegurar qualidade compatível dos recursos hídricos com os usos mais restritivos a que forem destinadas 


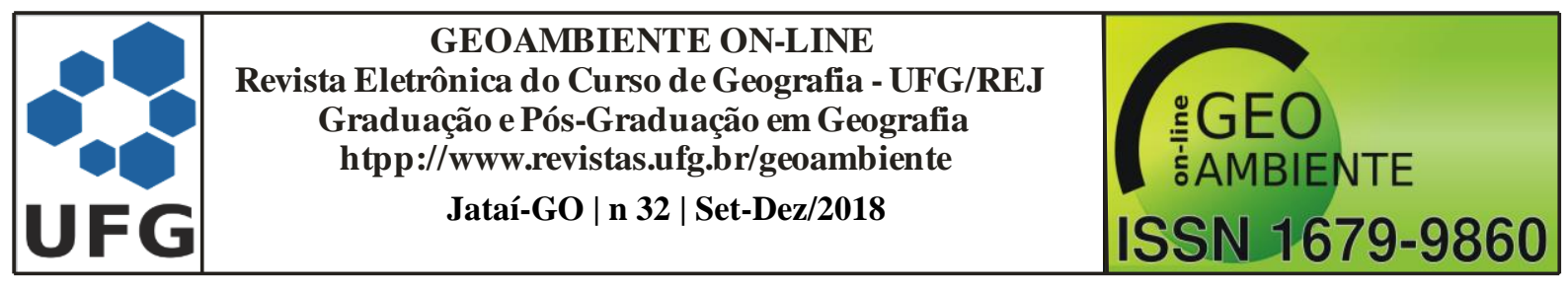

e diminuir os custos de combate à poluição das águas (BRASIL, 1997). O enquadramento dos corpos de água foi regulamentado por resoluções tanto do Conselho Nacional de Recursos Hídricos (CNRH) quanto do próprio Conselho Nacional de Meio Ambiente (CONAMA).

Com isso, o objetivo deste trabalho foi apresentar um levantamento dos aspectos históricos importantes sobre o enquadramento de corpos de água e como esses interage com outras políticas em âmbito Mundial, Nacional e Estadual para assegurar a manutenção dos padrões de qualidade dos recursos hídricos.

\section{ENQUADRAMENTO DOS CORPOS DE ÁGUA NO MUNDO}

Em muitos países o enquadramento de corpos de água se dá pelos usos desejados (ANA, 2005). Apresenta-se a seguir os normativos de quatro países para o enquadramento de corpos de água:

- Regulamento (CE) n ${ }^{\circ} 178$ do Parlamento e do Conselho Europeu de 28 de janeiro de 2002 estabelece os princípios e normas gerais para a Segurança dos Alimentos e processo para a segurança alimentar. Esse Regulamento trata também sobre o controle da qualidade da água destinada ao consumo humano dispõe das Diretivas 80/778 /CEE e 98/83 / CE do Conselho, a água deve estar conforme os termos do artigo $6^{\circ}$ da Diretiva 98/83 / CE (EUROPA, 2002).

- Decreto Legislativo $\mathrm{n}^{\circ} 31$ de 2001, este decreto regulamenta a qualidade "da água para consumo humano, a fim de proteger a saúde humana dos efeitos nocivos resultantes de qualquer contaminação da água, garantindo a salubridade" e limpeza (ITÁLIA, 2001).

- Decreto-Lei n ${ }^{\circ} 236$ de 1998, o presente diploma estabelece normas, critérios e objetivos de qualidade com a finalidade de proteger o meio aquático e melhorar a qualidade das águas em função dos seus principais usos (PORTUGAL, 1998).

- A Lei da Água Limpa estabelece a estrutura básica para regular as descargas de poluentes nas águas dos Estados Unidos e que regulamenta as normas de qualidade para as águas superficiais. A base da Lei da Água Limpa foi promulgada em 1948 e foi chamado de Lei de Controle de Poluição da Água Federal, mas a lei foi significativamente reorganizada e ampliada em 1972 (ESTADOS UNIDOS, 1972). 


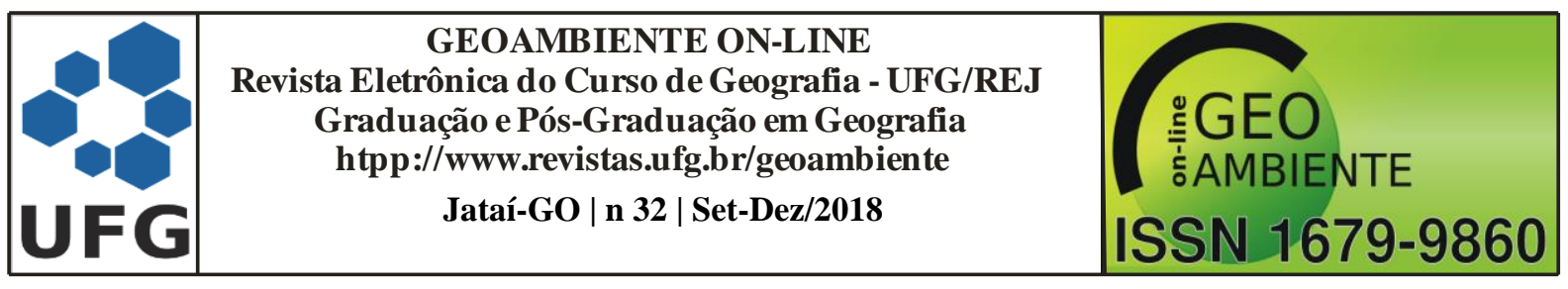

Outros países também apresentam legislação normativa sobre o enquadramento dos corpos de água que mesmo sem utilizar expressamente tal denominação como instrumento passam a apresentar mecanismos legais que asseguram a manutenção da qualidade das águas avaliando parâmetros físicos, químicos e biológicos.

O Canadá apresenta através de um conjunto de diretrizes elaborados em 1999 valores máximos permitidos para qualidade de águas destinadas a recreação, a proteção da vida aquática, para usos agrícolas entre outros (CCMMA, 2014).

No Japão é previsto através da Lei de Meio ambiente de 1992 a classificação dos corpos de água em seis classes de qualidade mediante a observância dos parâmetros pH, DBO, OD, sólidos em suspensão e coliformes fecais (PESSOA, 2013).

No Brasil é adotado o enquadramento de corpos de água por classes de qualidade. O enquadramento dos corpos de água por classes de qualidade visa manter o padrão de qualidade de um corpo hídrico ou alcançar um padrão desejado. Segundo a Agência Nacional de Águas esse padrão de qualidade da água está ligado à interação entre as condições do rio atual, o rio que o poder público e a sociedade desejam, sendo necessário a avaliação das limitações técnicas e econômicas para alcançar o padrão de qualidade da água desejada para o rio (ANA, 2005).

\section{ENQUADRAMENTO DOS CORPOS DE ÁGUA NO BRASIL}

Historicamente ao longo de 84 anos (período entre 1934 a 2018) se estabeleceram vários dispositivos legais sobre a questão da qualidade da água no Brasil. O primeiro dispositivo legal foi em 1934 com a instituição do Código de Águas que passou a ser especifico para os recursos hídricos (BRASIL, 1934). O primeiro enquadramento dos corpos de água em âmbito Federal ocorreu em 1976 pela Portaria de nº 013, que foi substituída pela Resolução CONAMA n 20 de 1986 (CONAMA, 1986). O Instituto Brasileiro de Meio Ambiente e dos Recursos Naturais realizou no ano de 1986 o enquadramento dos corpos de água de domínio da União na Bacia do Rio São Francisco de acordo com Resolução CONAMA nº 20 (ANA, 2005).

A Lei n ${ }^{\circ} 9.433$ de 1997, instituiu a Política Nacional de Recursos Hídricos (PNRH), o Sistema Nacional de Gerenciamento de Recursos Hídricos (SNGRH) e o Conselho Nacional de Recursos Hídricos (CNRH). Já a Lei no 9.984 de 2000, instituiu a Agência Nacional de Águas.

Os dispositivos criados na Lei de $n^{\circ} 9.433$ são regulamentados pelas Resoluções CONAMA no 357 de 2005 e nº 396 de 2008; e pela Resolução CNRH no 91 de 2008. Estas resoluções dispõem sobre a classificação dos corpos de água e diretrizes ambientais para o seu 


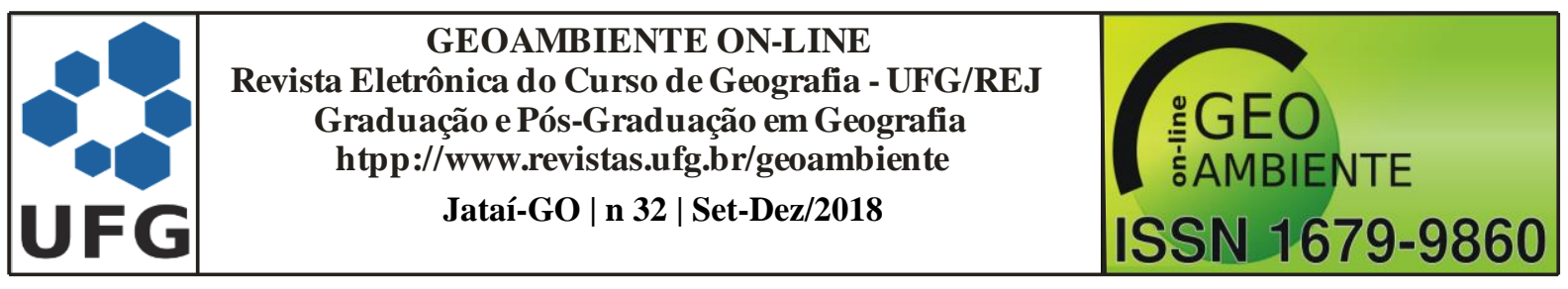

enquadramento, bem como estabelece as condições e padrões de lançamento de efluentes, e dá outras providências; classificação das águas subterrâneas e traça as diretrizes ambientais para o seu enquadramento; procedimentos gerais para o enquadramento dos corpos superficiais e subterrâneos.

Quando necessário essas resoluções passam por alterações, dessa maneira a Resolução CONAMA n 357 foi alterada pelas Resoluções $n^{\circ} 370$, de 2006, $n^{\circ} 397$, de 2008, $n^{\circ} 410$, de 2009, e nº 430, de 2011; e complementada pela Resolução nº 393 de 2009.

\section{Competência e propostas do enquadramento}

Segundo o art. 20 da Resolução CONAMA N 20, os órgãos competentes enquadrarão as águas e estabelecerão programas de controle de poluição para a efetivação dos respectivos enquadramentos. Os órgãos competes são: (i) $\mathrm{O}$ enquadramento das águas Federais na classificação será procedido pela Secretaria Estadual de Meio Ambiente; (ii) O enquadramento das águas Estaduais será efetuado pelo órgão estadual competente (CONAMA, 1986).

A seleção de proposta do enquadramento ocorre no âmbito do Comitê da Bacia Hidrográfica, composto por representantes da União, dos Estados, do Distrito Federal, dos municípios, dos usuários e das entidades civis de recursos hídricos com atuação comprovada na bacia (ANA, 2009; BRASIL, 1997). De modo a favorecer as discursões participativas, a estrutura de composição do Comitê de Bacia deve primordialmente adotar a atuação mais efetiva dos usuários e sociedade civil por serem diretamente afetadas pelas decisões consensadas, limitando a atuação do Poder Público até no máximo a metade do total de membros os quais podem ser definidos por processo eleitora previsto em edital (ANA, 2009; BRASIL, 1997).

Entretanto, não existe limitação percentual para composição dos Comitês previstos em Lei, devendo as estruturas se adequarem as necessidades existentes em cada Bacia Hidrográfica e quando necessário, decorrente de características especiais, solicitar também a participação dos representantes indígenas (FUNAI - Fundação Nacional do Índio e comunidades) na tomada de decisão, quando suas terras forem afetadas, sendo os corpos de águas de suas terras enquadrados em Classe 1 (ANA, 2009; BRASIL, 1997).

Os órgãos estaduais de meio ambiente e de recursos hídricos recebem diretrizes do Conselho Nacional de Recursos Hídricos ou Conselho Estadual de Recursos Hídricos e têm 


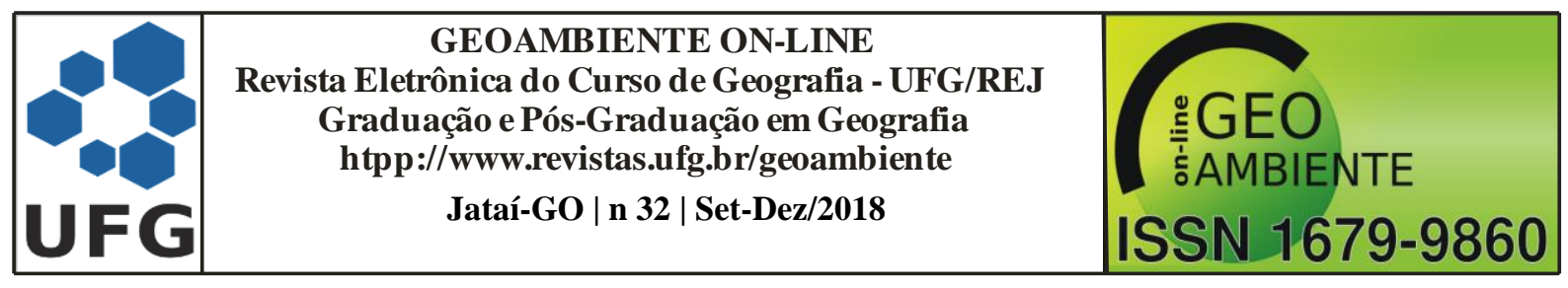

como competências o controle, o monitoramento e a fiscalização dos corpos de água, além da elaboração de estudos (ANA, 2005).

As propostas de enquadramento serão balizadas pela qualidade de água desejada mediante as atividades que se pretende executar na bacia hidrográfica. $\mathrm{O}$ monitoramento continuo dos recursos hídricos torna-se ferramenta essencial do enquadramento de corpos de água. Através desse é possível o estabelecimento de metas progressivas de melhoria da qualidade e visualização dos resultados obtidos favorecendo através de instrumentos de comando e controle o processo de melhoria dos recursos hídricos.

\section{Interação do enquadramento com outros instrumentos}

O enquadramento dos corpos de água exige a articulação das instituições de gerenciamento e dos colegiados do Sistema Nacional de Gerenciamento de Recursos Hídricos (SINGREH) e do Sistema Nacional de Meio Ambiente (SISNAMA). O enquadramento, assim como os planos de bacias hidrográficas, é referência para os demais instrumentos de gestão dos recursos hídricos e para os instrumentos de gestão ambiental, sendo, portanto, importante elo entre o SINGREH e o SISNAMA (ANA, 2009).

A Resolução CONAMA nº 357 de 2005 estabelece que as ações de gestão referentes ao uso dos recursos hídricos - tais como: a outorga e cobrança pelo uso da água, ou referentes à gestão ambiental, como o licenciamento, termos de ajustamento de conduta e o controle da poluição, deverão basear-se nas metas progressivas intermediárias e final aprovadas pelo órgão competente para a respectiva bacia hidrográfica ou corpo hídrico específico.

Outros instrumentos como o zoneamento ambiental, criação de espaços protegidos previstos na Política Nacional do Meio Ambiente Lei n 6938 de 1981, Plano Diretor Urbano previsto na Lei no 10257 de 2001 Estatuto das Cidades tendem a disciplinar a utilização do solo e verificar as suscetibilidades e restrições ao emprego das diferentes atividades. Tais verificações deverão ser correlacionadas a qualidade da água existente na bacia hidrográfica e verificar se os objetivos de melhoria de qualidade das águas previstos podem se conciliar ao desenvolvimento das atividades propostas atendendo ao enquadramento dos corpos de água desejado para os recursos hídricos.

Outro instrumento de planejamento que apresenta interdisciplinaridade com o enquadramento dos corpos de água é o Plano de Saneamento Básico previsto na lei $\mathrm{n}^{\circ} 11445$ de 2007. A existência de um plano de saneamento assegura o tratamento e disposição final 


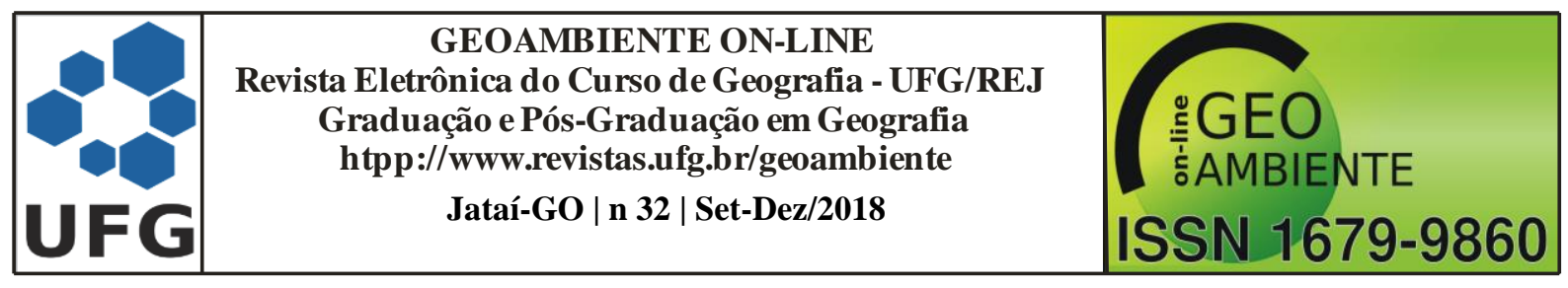

adequada dos resíduos sólidos, líquidos e gasosos produzidos no município. Dessa forma, quando objetiva-se o descarte de efluentes líquidos no recurso hídrico é possível assegurar através da elaboração e cumprimento do plano de saneamento que os efluentes destinados ao recurso hídrico não irão exceder as concentrações máximas permitidas de poluentes condizente com a qualidade da água desejada para a bacia hidrográfica.

Segundo Figueiró e Wolkmer (2013), a interação dos instrumentos previstos nas diferentes politicas é importante especialmente por que a articulações entre os planos de recursos hídricos, plano de saneamento, licenciamento e o enquadramento dos corpos d'água em classes de uso entre outros, repercutirá tanto no desenvolvimento econômico da região quanto na qualidade ambiental de determinada bacia hidrográfica.

Enquadramento de corpos de água doce, salobra, salina e subterrâneas.

O Conselho Nacional do Meio Ambiente, por meio da Resolução no 357 de 2005, dispõe sobre o enquadramento dos corpos de água doce, salobra e salina, e, as classificam em treze classes de qualidade. A Resolução no 396 de 2008 dispõe sobre a classificação e diretrizes ambientais para o enquadramento, prevenção e controle da poluição das águas subterrâneas e são classificadas em cinco classes.

A Resolução CONAMA n 357 de 2005 regulamenta dois importantes dispositivos da Lei das águas, sendo elas: assegurar às águas qualidade compatível com os usos mais exigentes a que forem destinadas e diminuir os custos de combate à poluição das águas. A Resolução CONAMA no 396 de 2008, estabelece que os órgãos ambientais em conjunto com os órgãos gestores dos recursos hídricos deverão promover a implementação de Áreas de Proteção de Aquíferos e Perímetros de Proteção de Poços de Abastecimento, objetivando a proteção da qualidade da água subterrânea.

As classes de enquadramento estão diretamente relacionadas à os parâmetros físicos, químicos e biológicos de qualidade, resguardando-se os valores máximos permitidos para casa classe de enquadramento (CONAMA, 2005). Uma vez que o enquadramento de um corpo de água é realizado para um trecho especificado é possível que um recurso hídrico possua mais de um enquadramento mediante o trecho em que se encontra sendo analisado (ANA, 2009).

O processo para a implementação do enquadramento dos corpos de água é dividido em cinco etapas segundo a Resolução CNRH n ${ }^{\circ} 91$ de 2008: diagnóstico da bacia; prognóstico da bacia; elaboração de proposta para enquadramento; análise e deliberações do Comitê da Bacia 


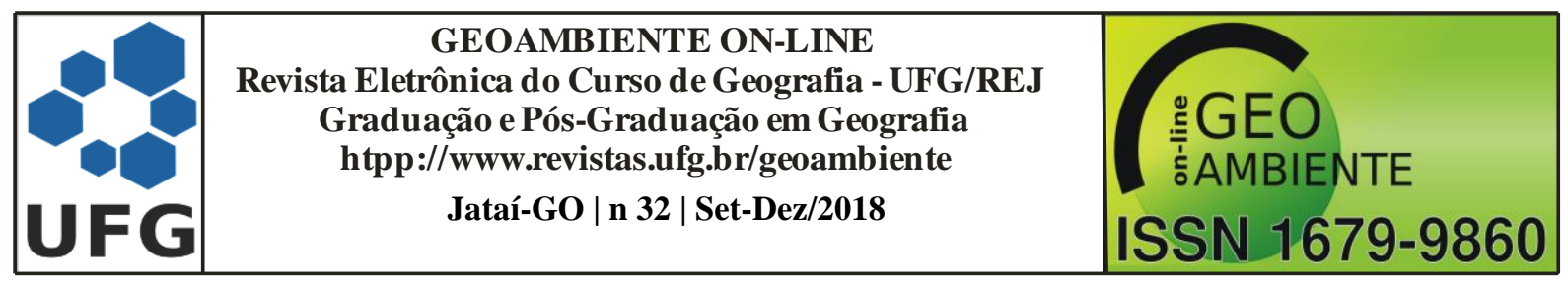

e do Conselho de Recursos Hídricos; e implementação do programa de efetivação. A identificação e deliberação do enquadramento da qualidade de água desejada para um corpo hídrico deverá ser um processo realizado de forma conjunta incorporando os comitês de bacia e os utilizadores dos recursos hídricos favorecendo assim o cumprimento das metas previstas de qualidade.

\section{ENQUADRAMENTO DOS CORPOS DE ÁGUA NO ESTADO DO CEARÁ}

O Estado do Ceará foi o pioneiro na criação da Política Estadual de Recursos Hídricos, através da Lei n 11.996 de 1992, assim, o Estado passou a regulamentar as atividades e os instrumentos que tratavam sobre esse tema. Entretanto, o instrumento de enquadramento de corpos de água, marco essencial para a manutenção e melhoria dos recursos hídricos, não se apresentava descrito nessa normativa (CEARÁ, 1992).

Contudo, o Estado do Ceará teve a adoção do instrumento de enquadramento de corpos de água quando a Política Estadual de Recursos Hídricos foi alterada pela Lei no 14.844 de 2010, sendo inserida no Artigo $5^{\circ}$ (CEARA, 2010). Mesmo assim, ainda é inexistente o enquadramento de corpos de água no Estado, este fato também foi verificado por Maia (2011) e Lima (2016).

Nesse contexto, mesmo com os avanços verificados na Lei atual, ainda carece de um Decreto-Lei que regulamente o processo de enquadramento de corpos de água no Estado do Ceará. Esta regulamentação anda em processo de análise, uma vez que os rios do Estado são intermitentes, e, assim, sendo inadequado enquadrar os corpos de água por meio dos dispositivos regulamentadores Nacional da atualidade. Verifica-se que é um processo de longo prazo, uma vez que, o primeiro Comitê de Bacia Hidrográfica ( $\mathrm{CBH}$ do Rio Curu) foi criado em 1992 e até o presente momento não foi estabelecido um Decreto-Lei, todavia, Já foram criados 12 Comitês de Bacias Hidrográficas no Estado do Ceará (CEARÁ, 2010; COGERH, 2016; CBH, 2018).

Embora as condições ambientais do semiárido seja uma barreira importante na aplicação das normativas em vigor, a Política Estadual de Recursos Hídricos do Ceará busca entre seus objetivo assegurar que a água, possa ser controlada e utilizada, em padrões de qualidade e quantidade satisfatórios, por seus usuários atuais e pelas gerações futuras, em todo o território do Estado do Ceará e planejar e gerenciar, de forma integrada, descentralizada e participativa, 


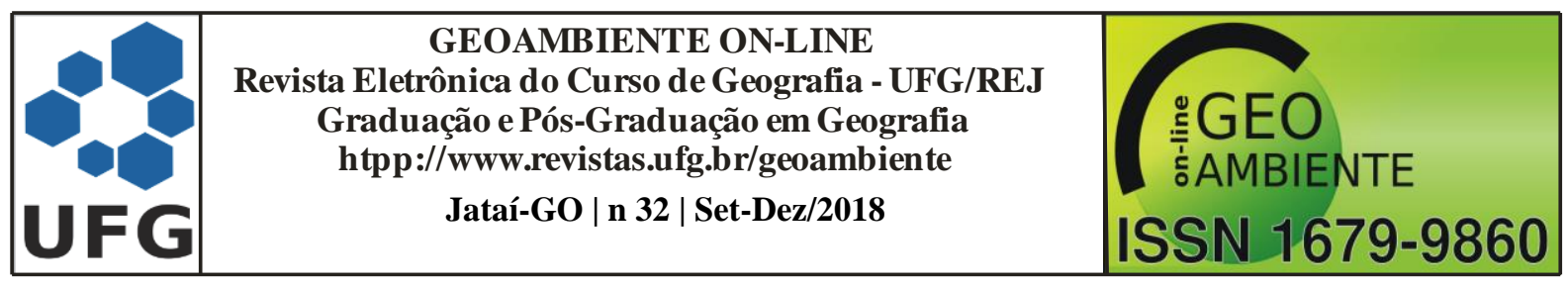

o uso múltiplo, controle, conservação, proteção e preservação dos recursos hídricos (CEARÁ, 2010).

O enquadramento dos corpos de água em classes de usos preponderantes é um instrumento da Política Estadual de Recursos Hídricos. No art. 16, constam os dispositivos que devem considerará em seus atributos a classe de uso preponderante em que for enquadrado o Corpo d'água onde se localiza o uso. O enquadramento de corpos de água visa assegurar a qualidade da água compatível com os usos mais exigentes a que forem destinados e diminuir os custos de combate à poluição das águas (CEARÁ, 2010).

Aprovar o enquadramento de corpos de água do domínio Estadual em classes de uso preponderante das Bacias Hidrográficas é uma das competências do Conselho de Recursos Hídricos do Ceará. Caberá à Secretaria dos Recursos Hídricos a instituição de equipes compostas por profissionais capacitados para exercer a fiscalização dos recursos hídricos, identificar as infrações, autuar e enquadrar nas penalidades cabíveis (CEARÁ, 2010).

\section{CONCLUSÃO}

O Enquadramento de Corpos de Água é um instrumento importante para assegurar os usos múltiplos de corpos de água, que requerem determinada qualidade para realização de diferentes atividades. A manutenção e melhoria da qualidade dos recursos hídricos, possibilitando assim que os demais instrumentos previstos em Lei sejam atendidos. Entretanto, podem ocorrer entraves em âmbito Estadual para implementação do enquadramento, como as condições hídricas do Semiárido.

\section{REFERÊNCIAS BIBLIOGRÁFICAS}

ANA - AGÊNCIA NACIONAL DE ÁGUAS. Implementação do enquadramento em bacias hidrográficas no Brasil; Sistema nacional de informações sobre recursos hídricos - Snirh no Brasil: arquitetura computacional e sistêmica. Cadernos de recursos hídricos. Brasília: ANA, 2009.

ANA - AGÊNCIA NACIONAL DE ÁGUAS. Panorama do enquadramento dos Corpos d'água. Cadernos de recursos hídricos. Brasília: ANA, 2007.

ANA - AGÊNCIA NACIONAL DE ÁGUAS. Panorama do enquadramento dos Corpos d'água. Cadernos de recursos hídricos. Brasília: ANA, 2005. 


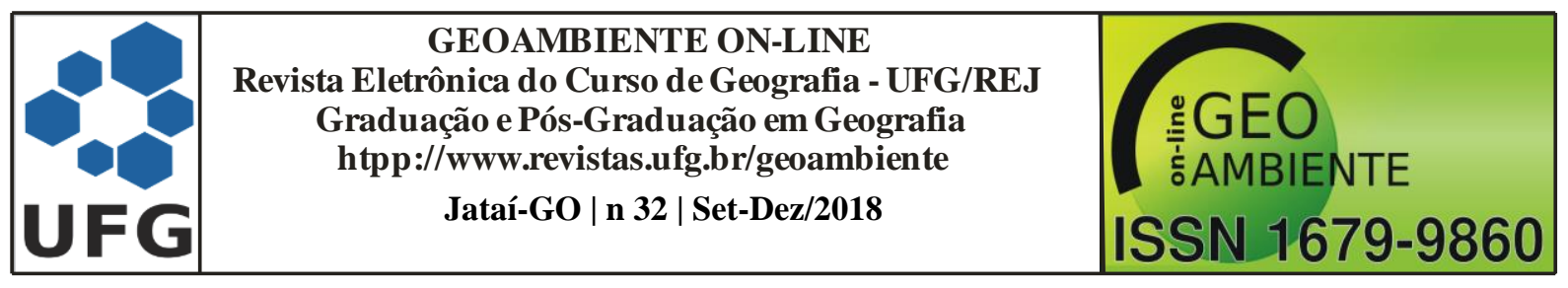

BARBOSA, Gisele Silva. O desafio do desenvolvimento sustentável. Revista Visões, [s.i], v. 1, p.1-11, 2008.

BRASIL. Lei $n^{o}$ 9.433, de 08 de janeiro de 1997. Institui a Política Nacional de Recursos Hídricos, cria o Sistema Nacional de Gerenciamento de Recursos Hídricos, regulamenta o inciso XIX do art. 21 da Constituição Federal, e altera o art. $1^{\circ}$ da Lei no 8.001, de 13 de março de 1990, que modificou a Lei $\mathrm{n}^{\mathbf{0}}$ 7.990, de 28 de dezembro de 1989. Disponível em <http://www.planalto.gov.br/ccivil_03/LEIS/L9433.htm>. Acessado em 20 de novembro de 2018.

BRASIL. Decreto $n^{o}$ 24.643, de 10 de julho de 1934. Considerando legislação adequada que, permita ao poder público controlar e incentivar o aproveitamento industrial das águas. Disponível em < http://www.planalto.gov.br/ccivil_03/decreto/D24643compilado.htm > Acessado em 07 de abril de 2016.

$\mathrm{CBH}-$ Comitês de Bacias Hidrográficas. CEARÁ. Disponível em <http://www.cbh.gov.br/DataGrid/GridCeara.aspx>. Acessado em 27 de novembro de 2018.

CEARÁ. LEI $N^{o}$ 14.844, de 30 de dezembro de 2010. Dispõe sobre a Política Estadual de Recursos Hídricos, institui o Sistema Integrado de Gestão de Recursos Hídricos - SIGERH, e dá outras providências. Disponível em <http://arquivos.ana.gov.br/institucional/sag/CobrancaUso/Legislacao/LeiCE_n_14.844_2812-10.pdf>. Acessado em 27 de novembro de 2018.

CEARÁ. LEI 11.996 de 29 de julho de 1992. Dispõe sobre a Política Estadual de Recursos Hídricos, institui o Sistema Integrado de Gestão de Recursos Hídricos - SIGERH e dá outras providências. Disponível em http://www.al.ce.gov.br/legislativo/tramitando/lei/me6671.htm>. Acessado em 25 de abril de 2016.

CNRH - Conselho Nacional de Recursos Hídricos. RESOLUÇÃO $N^{o}$ 91, DE 05 DE NOVEMBRO DE 2008. Dispõe sobre procedimentos gerais para o enquadramento dos corpos de água superficiais e subterrâneos. Disponível em $<$ http://portalpnqa.ana.gov.br/Publicacao/RESOLU\%C3\%87\%C3\%83O\%20CNRH\%20n\%C 2\%BA\%2091.pdf>. Acessado em 25 de abril de 2016.

CONAMA - Conselho Nacional de Meio Ambiente. RESOLUÇÃO No 430, DE 13 DE MAIO DE 2011. Dispõe sobre as condições e padrões de lançamento de efluentes, complementa e altera a Resolução no 357, de 17 de março de 2005, do Conselho Nacional do Meio Ambiente- 


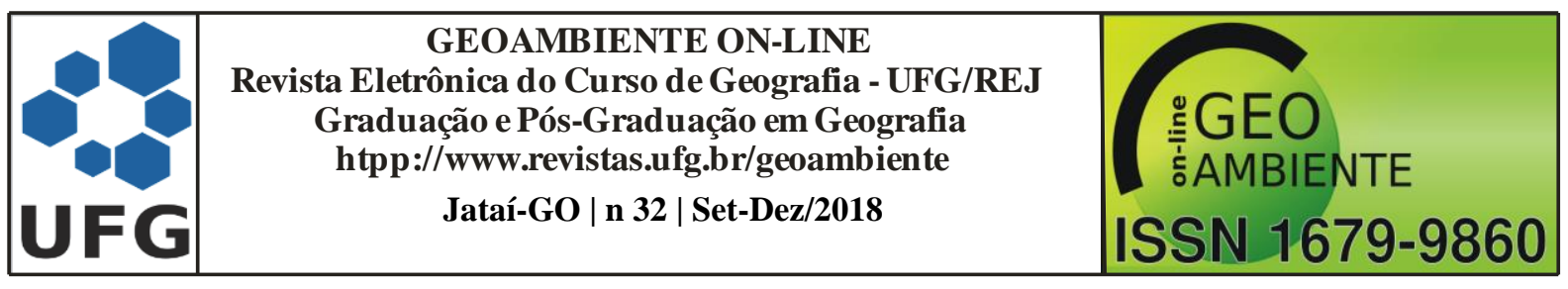

CONAMA.

Disponível

em

http://www.mma.gov.br/port/conama/legiabre.cfm?codlegi=646>. Acessado em 25 de abril de 2016.

CONAMA - Conselho Nacional de Meio Ambiente. RESOLUÇÃO CONAMA $n^{\circ}$ 396, de 3 de abril de 2008. Dispõe sobre a classificação e diretrizes ambientais para o enquadramento das águas subterrâneas e dá outras providências. Disponível em < http://www.mma.gov.br/port/conama/legiabre.cfm?codlegi=562>. Acessado em 25 de abril de 2016.

CONAMA - Conselho Nacional de Meio Ambiente. RESOLUÇÃO N ${ }^{o}$ 357, DE 17 DE MARÇO DE 2005. Dispõe sobre a classificação dos corpos de água e diretrizes ambientais para o seu enquadramento, bem como estabelece as condições e padrões de lançamento de efluentes, e dá outras providências. $\quad$ Disponível em http://www.mma.gov.br/port/conama/res/res05/res35705.pdf> acessado em 10 de maio de 2016.

CONAMA - Conselho Nacional de Meio Ambiente. RESOLUÇÃO CONAMA N 20, de 18 de junho de 1986. Estabelecer a seguinte classificação das águas, doces, salobras e salinas do Território Nacional. Disponível em < http://www.mma.gov.br/port/conama/res/res86/res2086.html> acessado em 16 de maio de 2016.

CCMMA - Conselho Canadense de Ministros do Meio Ambiente. Diretrizes Canadenses de Qualidade Ambiental. 2014. Disponível em: 〈http://ceqg-rcqe.ccme.ca/en/index.html\#void>. Acesso em: 21 ago. 2018.

ESTADOS UNIDOS. United States Environmental Protection Agency. Summary of the Clean Water Act. 33 U.S.C. $\$ 1251$ et seq. (1972). Disponível em < https://www.epa.gov/lawsregulations/summary-clean-water-act > acessado em 06 de maio de 2016.

EUROPA. VERORDNUNG (EG) Nr. 178/2002 DES EUROPÄISCHEN PARLAMENTS UND DES RATES. Zur Festlegung der allgemeinen Grundsätze und Anforderungen des Lebensmittelrechts, zur Errichtung der Europäischen Behörde für Lebensmittelsicherheit und zur Festlegung von Verfahren zur Lebensmittelsicherheit. (ABl. L 31 vom 1.2.2002, S. 1). Disponível em http://eurlex.europa.eu/LexUriServ/LexUriServ.do?uri=CONSLEG:2002R0178:20080325:de:PDF>; acessado em 06 de maio de 2016. 


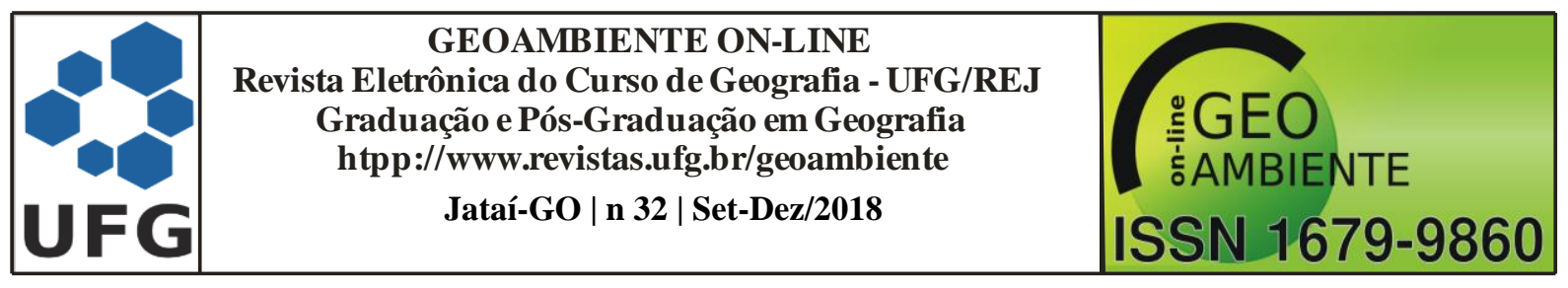

FIGUEIRÓ, F.; WOLKMER, M. de F. S. A interface da água enquanto recurso ambiental e econômico e a sua interconexão com a tutela do meio ambiente. Revista Jurídica - CCJ, ISSN 1982-4858 v. 17, no. 34, p. 37 - 56, jul./dez. 2013.

ITÁLIA. Decreto Legislativo 2 febbraio 2001, n. 31. Pubblicato nella Gazzetta Ufficiale n. 52 del 3 marzo 2001 - Supplemento Ordinario $n$. 41. Disponível em < http://www.camera.it/parlam/leggi/deleghe/01031dl.htm>; acessado em 06 de maio de 2016.

LIMA, Berthyer Peixoto. Enquadramento de corpos d'água no Nordeste brasileiro como instrumento de gestão e sustentabilidade ambiental: o caso da bacia hidrográfica Acarape do Meio - CE. Tese (Doutorado em Engenharia Agrícola) - Universidade Federal do Ceará, Fortaleza, 2016. 272 p.

MAIA, Judária Augusta. Qualidade ambiental e nível de eutrofização do Rio Maranguapinho na região metropolitana de Fortaleza-CE. Dissertação (Mestrado em Geografia) Universidade Estadual do Ceará. Fortaleza-CE, 2011. 144 pág.

PESSÔA, Zúri Bao. Efetivação do enquadramento de corpos d'água para fins de consumo humano em regiões semiáridas: avaliação conforme resolução conama 357/2005 e portaria ms 2914/2011. Dissertação (Mestrado em Meio Ambiente, Águas e Saneamento) Universidade Federal da Bahia, Escola Politécnica. Salvador, 2013. 124 pág.

PORTUGAL. Ministério do Ambiente. Monitorização/Normas de Qualidade. Decreto-Lei $n^{o}$ 236 de 1998. Diário da República — I serie-A. No 176 - 1-8-1998. Disponível em $<$ http://www.apambiente.pt/index.php?ref=16\&subref=7\&sub2ref=15\&sub3ref=93>; acessado em 06 de maio de 2016. 